\title{
Research on Technical Route Optimization and Energy-saving Characteristics of High-temperature Subcritical Retrofit
}

\author{
HE An Wu ${ }^{1, a}$, FENG Wei Zhong ${ }^{2, b^{*}}, \mathrm{Y} \mathrm{Li}^{1}$ \\ ${ }^{1}$ Shanghai University of Electric Power, Shanghai 201306, China. \\ 2 Shanghai Waigaoqiao No.3 Power Generation Co., Ltd.2, Shanghai 200137, China.
}

\begin{abstract}
In order to further reduce the power supply coal consumption rate for $300 \mathrm{MW}$ subcritical units, this paper will conduct a comprehensive analysis to improve the main steam and reheat steam parameters of those units based on the basic principles of thermodynamics, steam turbines and water pumps. The analysis shows that for the subcritical unit retrofit method that only raises the main steam and reheat steam temperature as the basic technical route has better feasibility. On this basis, combined with the actual system and working conditions of the $320 \mathrm{MW}$ subcritical unit, a simulation model of the entire plant's thermal system is established for calculation and analysis. The calculation results show that the heat consumption rate of the high-temperature subcritical retrofit can reach $7526.7 \mathrm{~kJ} / \mathrm{kWh}$. Combined with China Resources Xuzhou \#3 unit high temperature subcritical comprehensive retrofit project (using high temperature subcritical transformation and equipped with special energy saving transformation), A comprehensive analysis of the performance of the unit after retrofit. The analysis shows that the coal consumption rate after the retrofit is reduced by $36 \mathrm{~g} / \mathrm{kWh}$.
\end{abstract}

\section{Introduction}

Under the trend of global warming, the coal power industry, is sustain great pressure to reduce emissions ${ }^{1}$. Considering China's special energy structure, even in the future for a long time, coal power will still occupy the main position ${ }^{2}$. In order to further improve the efficiency of coal-fired power plants, the National Energy Administration and other three ministries issued a document named the "Six Year Action Plan" in 2014, which required that the annual average power consumption of coal-fired units with a capacity of $300 \mathrm{MW}$ should be less than $310 \mathrm{~g} / \mathrm{kWh}^{3}$. However, the actual annual average coal consumption of most $300 \mathrm{MW}$ subcritical units is about $340 \mathrm{~g} / \mathrm{kWh}^{4}$. In the face of a large number of $300 \mathrm{MW}$ subcritical units ${ }^{5}$, which have better economic benefits in the grid peak regulation, it is obviously unreasonable to shut down all the units. Thus, high efficiency retrofit is necessary for these subcritical units.

At present, domestic and foreign research institutions have carried out more research on the retrofit of subcritical units. The efficiency of the turbine can be increased by $2 \% \sim 2.6 \%$ after the whole turbine has been reformed by Hitachi ${ }^{6}$. During the period from 2007 to 2012 in China, the early 300MW grade turbines put into production have been large scale flow path retrofit? However, for the subcritical turbine flow path retrofit project, the domestic turbine manufacturers generally have the prominent problems that the turbine efficiency declines rapidly ${ }^{8-9}$. Subcritical cross-generation retrofit technology; domestic scientific research institutes have a certain theoretical research ${ }^{10-11}$.

The existing retrofit solution of subcritical units are mostly divided into three kinds. First, power cycles the system optimization, such as the steam turbine flow path retrofit; Second, the "double lift" retrofit of the initial parameters, such as the upgrade parameter retrofit; Third, Rankine cycle optimization, such as secondary reheat retrofit. There are few "single-lift" modifications of initial and reheat parameters, especially retrofit that only increase the main steam and reheat steam temperature.

Based on thermodynamics, basic principles, this paper analyzes the feasibility of the "single lift" retrofit, and combined with the actual case unit simulation. The results show that the heat consumption rate of the high temperature subcritical transformation can reach $7526.7 \mathrm{~kJ} / \mathrm{kWh}$ based on the technical route of only increasing the temperature of main steam and reheat steam. Combined with the case analysis of China Resources Xuzhou example hightemperature subcritical comprehensive retrofit (Adopt high temperature subcritical retrofit, and equipped with special energy-saving transformation), the coal consumption rate decreases by $36 \mathrm{~g} / \mathrm{kWh}$ after transformation, and the coal consumption rate can reach $281.95 \mathrm{~g} / \mathrm{kWh}$.

\footnotetext{
Corresponding author: ${ }^{\mathrm{b}} 002 @ w g q 3 . c o m$

a heanwu95@163.com

liyandy2000@sina.com
} 


\section{TO IMPROVE THE SENSITIVE AND FEASIBILITY ANALYSIS OF MAIN STEAM AND REHEAT STEAM PARAMETERS}

\subsection{Influence on relative internal efficiency of steam turbine}

\subsubsection{Improve the influence of main steam pressure on internal efficiency}

Steam leakage loss at the top of steam turbine ${ }^{12}$ can be expressed as:

$$
\delta h_{\mathrm{t}}=\frac{\mu_{1} \overline{\delta_{\mathrm{z}}} \psi_{\mathrm{t}}}{\mu_{2} \sin \alpha_{1}} \Delta h_{1}{ }^{\prime}
$$

Where $\delta h_{t}$ is steam leakage loss at the top of movingblade; $\overline{\delta_{z}}$ is ratio of tip axial clearance $\delta z$ to movingblade height $\mathrm{lb} ; \psi_{\mathrm{t}}$ is reaction $\Omega_{\mathrm{m}}$ and seal tooth of the average diameter $\mathrm{d}_{\mathrm{b}} / \mathrm{l}_{\mathrm{b}}$ related empirical coefficient; $\mu_{1}$ is an empirical coefficient related to $\delta z$ and the thickness of the girth edge $\Delta \mathrm{s} ; \mu_{2}$ is an empirical coefficient related to $\delta_{\mathrm{z}}$ and speed ratio $u / c_{\mathrm{a}} ; \alpha_{1}$ is nozzle outlet steam flow angle; $\Delta \mathrm{h}_{1}{ }^{\prime}$ is effective specific enthalpy drop at the stage without steam leakage loss.

It can be seen from Equation (1). The tip loss $\delta h_{\mathrm{t}}$ is strongly correlated with the reciprocal $1 / l_{\mathrm{b}}$ of blade height. When the subcritical main steam pressure of $16.7 \mathrm{MPa}$ is increased to $26 \mathrm{MPa}$, the volumetric flow rate decreases by $40.8 \%$, the blade height of the inlet side of the high-pressure cylinder of the steam turbine decreases accordingly, the steam leakage loss increases, and the relative internal efficiency of the steam turbine decreases.

For $300 \mathrm{MW}$ grade subcritical steam turbine, the mass flow of main steam is small, and the blade on the inlet side is short. In this capacity class unit, the stage efficiency decline caused by end loss is very sensitive to the blade height. When the pressure increases substantially, the blade shortens correspondingly, the ratio of end loss increases significantly, and the relative internal efficiency of the turbine decreases.

In addition, steam turbine moisture loss can be expressed as ${ }^{12}$ :

$$
\delta h_{\mathrm{x}}=\left(1-x_{\mathrm{m}}\right) \Delta h_{\mathrm{i}}{ }^{\prime}
$$

Where $\delta h_{\mathrm{x}}$ is moisture loss; $\Delta \mathrm{h}_{\mathrm{i}}{ }^{\prime}$ is effective specific enthalpy drop at stages without moisture loss; and $x_{\mathrm{m}}$ is average steam dryness within the stage.

$$
x_{\mathrm{m}}=\frac{s_{\mathrm{x}}-s^{\prime}}{s^{\prime \prime}-s^{\prime}}
$$

Where $s_{\mathrm{x}}$ is the exhaust steam entropy; $\mathrm{s}$ " is entropy of dry saturated steam at exhaust pressure; $s$ ' is entropy of saturated water at exhaust pressure.

When the main steam pressure increases and the reheat steam pressure increases correspondingly, the exhaust steam dryness decreases, the low-pressure cylinder moisture loss increases, and the low-pressure cylinder efficiency decreases accordingly.
2.1.2 Improve the influence of main steam and reheat steam temperature on internal efficiency

When the main steam and reheat steam temperature is raised to $600^{\circ} \mathrm{C}$, the volume flow increases by $11.7 \%$, and the blade height at the inlet side of the turbine increases accordingly. The relative internal efficiency of the turbine is improved.

In addition, the reheat steam temperature increases, the steam turbine exhaust dryness increases, the lowpressure cylinder moisture loss is reduced, the lowpressure cylinder efficiency is improved.

\subsection{Comprehensive feasibility analysis of improving main steam parameters}

For $300 \mathrm{MW}$ class units, the main steam temperature is kept constant and the main steam pressure is increased. Although the circulation efficiency increases, the relative internal efficiency of the turbine decreases. At the same time, related to the pressure of other equipment need comprehensive change, the cost performance is very low.

But, increasing the main steam temperature and reheat steam temperature alone will increase the cycle efficiency and bring additional benefits to the internal efficiency of steam turbine. In addition, the main steam and reheat steam pressure is unchanged, can maximize the use of the original system. Therefore, the retrofit method that only increases the main steam and reheat steam temperature as the basic technical route has better feasibility.

\section{Superiority analysis of high temperature subcritical retrofit}

For $300 \mathrm{MW}$ subcritical unit, it is more feasible to improve the temperature of main steam and reheat steam. The high temperature subcritical retrofit scheme is put forward on this basis, and its technical route is: The temperature of the main steam and reheat steam of the boiler is raised to $600^{\circ} \mathrm{C}$ of the current ultra-supercritical level through the retrofit of the superheater and reheater, keeping the pressure unchanged, and the steam turbine has been retrofit into high temperature and high efficiency.

\subsection{The advantage analysis only considers the improvement of cycle efficiency}

Combined with the actual operating conditions of a $320 \mathrm{MW}$ unit, the energy saving characteristics of the high temperature transformation were analysed and calculated. The basic idea is to use MATLAB programming software to establish the calculation model of the whole plant's thermal system based on the working conditions before the retrofit of the case unit ${ }^{13}$. On this basis, the parameters of main steam and reheated steam were gradually increased (only the influence of increasing parameters on cycle efficiency was considered), and the gains of specific heat consumption and net efficiency under pressure and temperature 
changes were obtained respectively, and the calculation results were shown as Fig. 1 follows:

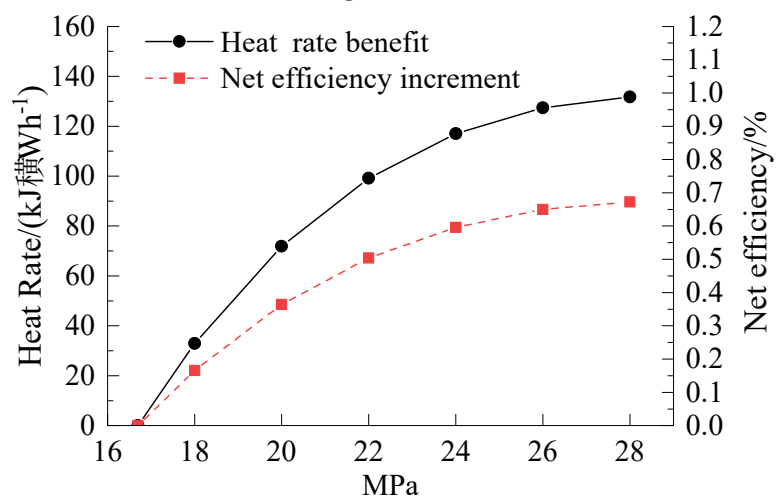

a)Increase the main steam pressure

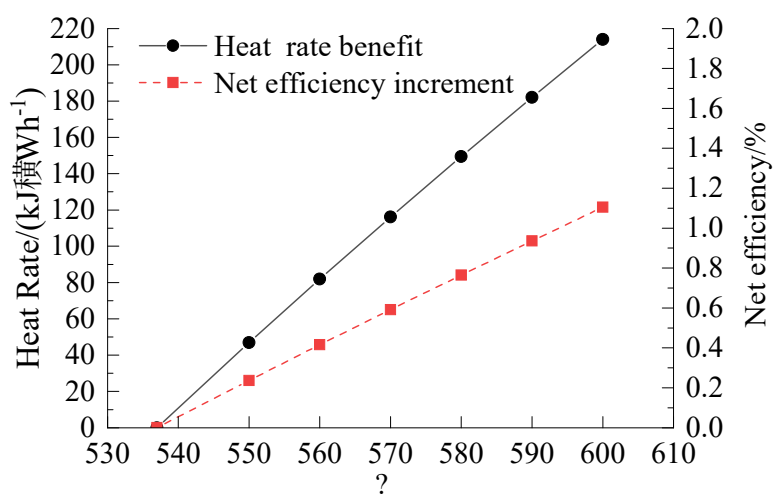

b)Increase main steam and reheat steam temperature

Fig. 1Improve main steam and reheat steam parameters

Fig. 1 a) shows that when the main steam pressure increases from $16.7 \mathrm{MPa}$ to $26 \mathrm{MPa}$, the benefit increment of unit specific heat consumption gradually converges, and the net efficiency of the unit only increases by about $0.65 \%$. As can be seen from Fig. 1(b), when the main/reheat steam temperature increases from $537^{\circ} \mathrm{C}$ to

Table 1:

Table 1 Simulation results

\begin{tabular}{|c|c|c|c|c|}
\hline \multirow{3}{*}{ Item } & \multicolumn{4}{|c|}{ high temperature subcritical retrofit } \\
\hline & \multirow{2}{*}{$\begin{array}{c}\text { The } \\
\text { main/reheat } \\
\text { steam } \\
\text { temperatur } \\
\text { e is raised } \\
\text { to } 600^{\circ} \mathrm{C}\end{array}$} & \multicolumn{2}{|c|}{$\begin{array}{l}\text { High temperature retrofit } \\
\text { and high efficiency retrofit } \\
\text { of steam turbine flow part }\end{array}$} & \multirow{2}{*}{$\begin{array}{c}\text { Raise feed } \\
\text { temperature }\end{array}$} \\
\hline & & $\begin{array}{c}\text { Equivalent } \\
\text { to } \\
\text { traditional } \\
\text { flow retrofit }\end{array}$ & $\begin{array}{c}\text { Additional } \\
\text { benefits of } \\
\text { high } \\
\text { temperature }\end{array}$ & \\
\hline $\begin{array}{l}\text { Heat rate } \\
\left(\mathrm{kJ} \cdot \mathrm{kWh}^{-1}\right)\end{array}$ & 7944.3 & 7757.8 & 7602.2 & 7526.7 \\
\hline $\begin{array}{c}\text { Net efficiency } \\
/ \%\end{array}$ & 39.42 & 40.6 & 41.61 & 42.06 \\
\hline $\begin{array}{c}\text { Net efficiency } \\
\text { benefit } / \%\end{array}$ & 1.02 & 2.2 & 3.21 & 3.66 \\
\hline $\begin{array}{l}\text { Net efficiency } \\
\text { increment } / \%\end{array}$ & 1.02 & 1.18 & 1.01 & 0.45 \\
\hline
\end{tabular}

Note: the net efficiency of $300 \mathrm{MW}$ subcritical unit under rated working condition is $38.4 \%$ as the benchmark.

As can be seen from

Table 1, if the internal efficiency benefit of equivalent conventional flow retrofit are not included, the comprehensive net efficiency benefit of turbine's high-temperature transformation are $2.48 \%$, while the $600^{\circ} \mathrm{C}$, the unit efficiency gains increase linearly and the net efficiency increases by more than $1 \%$.

\subsection{Advantage analysis considering internal efficiency change and thermodynamic system optimization}

In fact, due to the major steam and reheat steam temperature increase, the steam turbine flow part must be replaced, equivalent to the flow path retrofit.

In addition, the internal efficiency benefit by the high temperature and high efficiency retrofit of steam turbines include two aspects: First, it is equivalent to the internal efficiency benefit obtained by the traditional flow transformation; Second, high temperature steam turbine additional efficiency improvement.

Besides, in order to cooperate with the heating retrofit of the boiler, it is necessary to increase the feed water temperature, so the first stage high pressure heater is added, thus further improving the average heat absorption temperature of the boiler and the net efficiency of the unit.

By means of modelling and simulation, the energy saving characteristics of turbine internal efficiency improvement and adding high pressure heater are analysed. The calculation idea is to establish a thermodynamic system calculation model of the whole plant, which only increases the main steam and reheat steam temperature to $600^{\circ} \mathrm{C}$ (considering only the influence on cycle efficiency). On this basis, the internal efficiency increments of the turbine which is equivalent to that obtained by the traditional through-flow modification is considered first; In addition, the internal efficiency of the turbine is improved due to the heating; Finally, consider the effect of increasing feed water temperature on unit efficiency. Simulation results are as follows 


\section{Example analysis of high temperature subcritical retrofit}

The Unit 3 of China Resources Power (Xuzhou) Co., Ltd Tongshan Power Plant was put into operation in 2004. In 2012, HP-IP turbine flow paths modification, and in 2017 , the performance test was carried out. In addition to the heating retrofit, the project also loaded a series of special energy-saving technical retrofit ${ }^{14}$. The result is shown in Fig. 2:

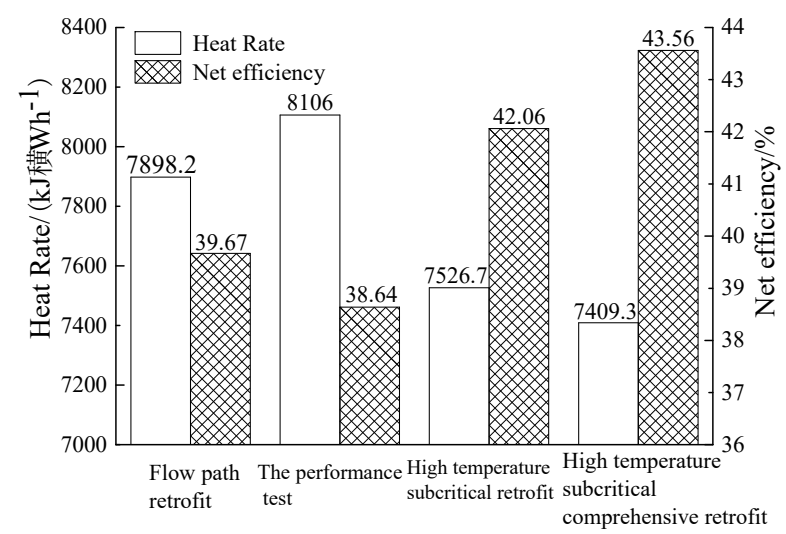

Fig. 2 Calculation and test results

As can be seen from Fig. 2, the net efficiency of the unit has decreased by $1.03 \%$ after 5 years of operation after the HP-IP turbine flow paths modification. The performance test shows that the net efficiency is $43.56 \%$ and the coal consumption of power supply is $281.95 \mathrm{~g} / \mathrm{kWh}$ under the rated working condition after the modification. Compared with the performance test before the 2017 retrofit, the net efficiency increased by $4.94 \%$ and the coal consumption decreased by $36 \mathrm{~g} / \mathrm{kWh}$. If the unit is not reformed by flow, the coal consumption will decrease by more than $40 \mathrm{~g} / \mathrm{kWh}$.

\section{5 conclusion}

(1) Due to the increase of main steam temperature, the heat consumption of $300 \mathrm{MW}$ steam turbine can reach $7526.7 \mathrm{~kJ} / \mathrm{kWh}$. After loading a series of energy-saving technologies, the power supply coal consumption rate of $320 \mathrm{MW}$ subcritical unit is lower than $282 \mathrm{~g} / \mathrm{kWh}$ under rated working conditions.

(2) If the high-temperature subcritical retrofitting technology can be fully applied in China, the annual energy saving will be more than 58 million tons of standard coal, emission reduction of carbon dioxide will be more than 156 million tons, according to the estimate of the energy saving of a single unit of at least $35 \mathrm{~g} / \mathrm{kW}$.

\section{Acknowledgments}

This paper is one of the periodic results of " Project of Shanghai Municipal Science and Technology Commission" (20dz1205208).

\section{References}

1. PENG Weihua. Carbon Dioxide Emission Reduction Technologies for Coal-fired Power Plants [J]. Guangdong Chemical Industry. 2012. 39(05):164165.

2. KANG Junjie, WANG Yihui, LI Jingjing, ZHANG Weirong. China coal power development status and trend analysis and positions outlook[J]. Energy of China. 2019, 41(08):9-13.

3. National Development and Reform Commission, Ministry of Environmental Protection, National Energy Administration. Notice on the issuance of the Action Plan for Upgrading and Transformation of Coal Power Energy Conservation and Emission Reduction (2014-2020) (Fagai [2014] No. 2093) [Z]. National Development and Reform Commission.

4. MAO Jianxiong: What is the future of coal power technology under the guidance of "30 $60 "$ goal.[N]. China Electric Power News.

5. MI Di. Xuzhou China Resources No. 3 unit reached the ultra-supercritical level [N]. CHINA ENERGY NEWS, 2019, The 11th edition.

6. PENG Sheng. Technical Analysis of modification of 300MW turbine flow paths Unit [J]. Science and Technology. 2014, (12):82+84.

7. TAN Rui, XU Xing, SHAO Feng, et al. Review of the Flow Path Retrofit of 300MW Class Subcritical Steam Turbine [J]. Turbine Technology, 2017, 59(04):291-294.

8. LI Guoming, XIE Cheng, ZHENG Lei, et al. Discussion on Typical Issues in Large Steam Turbine Retrofit [J]. Steam Turbine Technology, 2019, 61(06):473-475+478.

9. YANG Leilei, WANGYan, ZHANG Guo-zhu, et al. The description of energy reconstruction for 300MW subcritical units[J]. ENERGY CONSERVATION

10. WU Yiqiang, SHU Junzhan. A Brief Discussion on the Retrofit Scheme of Domestic Subcritical 300MW Units by Upgrading Them into Serial UltraSupercritical Cycle Unit[J]. China Electric Power Industry (Technical Edition), 2011(01):33-37.

11. XIE Da-xing, SHI Yong-feng, HAO Jian-gang, ZHENG Jian, CHEN You-liang, LEI Jiao-jiaop[J]. Application of Cross-generation Upgrade Reconstruction Technology in the $600 \mathrm{MW}$ Subcritical Unit, 2015, 36(06): 23-26.

12. SHEN Shiyi Etc. Principles of Steam Turbine [M]. China Electric Power Press, 1992.06.

13. HUANG Xinyuan. Designing Project for Thermal Power Plants [M]. China Electric Power Press, 2015.08 .

14. FENG Weizhong. China's national demonstration project achieves around 50\% net efficiency with $600^{\circ} \mathrm{C}$ class materials[J]. Fuel, 223(2018)344-353. 